\title{
ACCOMMODATION RESPONSE AND SPHERICAL ABERRATION DURING ORTHOKERATOLOGY
}

\section{Batres L ${ }^{1,2}$ MSc, Peruzzo ${ }^{1}$ MSc, Serramito $M^{1}$ MSc, Carracedo G ${ }^{1}$ PhD}

${ }^{1}$ Department of Optics II (Optometry and Vision), Faculty of Optics and Optometry, Complutense University of Madrid, Madrid, Spain

${ }^{2}$ Ophthalmological Clinic Doctor Lens, Madrid, Spain

Disclosure: The authors do not have any financial interest in the materials and instruments used in this study

\section{Corresponding Author:}

Gonzalo Carracedo Rodríguez Faculty of Optic and Optometry

Department of Optometry and Vision University Complutense of Madrid C/Arcos del Jalon 118 28032 (Madrid) Spain e-mail: jgcarrac@ucm.es 


\begin{abstract}
Purpose: To evaluate the changes in the accommodative response and in the corneal and internal spherical aberration during three months of wear of orthokeratology lenses from the baseline.
\end{abstract}

Methods: Fifty children aged 8 to 17 were recruited for a prospective study and were fitted with orthokeratology lenses. Refraction without cycloplegia, high and low uncorrected visual acuity (UCVA), best corrected visual acuity (BCVA), accommodation lag, horizontal near phoria without correction, corneal topography, corneal and total wavefront aberration were performed at baseline, 1 day, 1 week, 1 month and 3 months. Data were analysed by Student t-test for related samples, repeated measures ANOVA test and Pearson Correlation test.

Results: The spherical equivalent (SE) before and after three months was $-3.33 \pm 1.60 \mathrm{D}$ and $-0.30 \pm 0.46 \mathrm{D}$, respectively. Accommodation lag was $0.53 \pm 0.38 \mathrm{D}$ and $0.20 \pm 0.33 \mathrm{D}$ at baseline and at three months, respectively. A moderate correlation between lag at the baseline and its change between baseline and the 3-month visit was found $(\mathrm{P}<0.05 ; \mathrm{R}=$ 0.748). The spherical aberration (SA) increased for anterior corneal and total measurement, being statistically significant for all visits $(\mathrm{P}<0.05)$. The internal SA decreased: $-0.105 \pm 0.006$ at baseline and $-0.196 \pm 0.203$ at 1 week $(\mathrm{P}<0.05)$. No difference between baseline and the follow up visits in posterior corneal SA was found $(\mathrm{P}>0.05)$

Conclusion: The negative SA of the lens increases during OK treatment compensated for the increase of the anterior corneal surface positive SA, in addition to increasing the accommodative response.

Key Words: myopia; orthokeratology; aberrations; accommodation 


\section{INTRODUCTION}

Myopia is the most common refractive error among adolescents and young adults around the world [1-3]. The prevalence of myopia has increased in recent years and will continue to increase in the future $[4,5]$. It is estimated that by $2050,50 \%$ of the world population will be myopic, affecting six billion people, of which almost one billion will have high myopia [4]. Several studies have shown that a higher degree of myopia corresponds to a higher risk of complications, and this risk increases exponentially if -6 D (high myopia) are exceeded $[3,6,7]$.

Many epidemiological studies have found that myopia develops primarily in an eye that is excessively elongated axially [8]. The mechanism and the reasons why myopia increases is as yet unknown $[9,10]$. Several influencing factors have been identified which influence myopia progression: genetic predisposition [9, 11-13] and environment factors and lifestyle, such as spending little time outdoors and/or too much time spent indoors using near vision [14-16]. However, other studies [17] allude to an inadequate near accommodative response [17-22], high AC/A [23, 24], esophoria and peripheral hyperopic defocus as being risk factors in myopia progression [25-29] .

For years, different optical correction (monofocal, bifocal, progressive glasses, soft contact lenses with peripheral defocus, multifocal, rigid gas permeable (RGP) contact lens, bifocal RPG and orthokeratology lenses Reference needed and / or drugs (atropine at different concentrations $1.0 \%, 0.5 \%, 0.1 \%$ and $0.01 \%$, cyclopentolate and pirenzepine) have been studied in controlling myopic progression [29-31]. The most effective optical method for myopia control [31] has been orthokeratology lenses [32-35] and soft contact lenses based on peripheral defocus [36, 37].

Orthokeratology $(\mathrm{OK})$ is a technique for the temporary reduction of myopia by applying contact lenses overnight which reshape the corneal surface [38]. Swarbrick et al. found 
that there are no significant changes in the posterior curvature of the cornea, only finding changes on the anterior surface [39].

The corneal reshaping due to the OK lenses decreases the corneal asphericity and, in the case of myopia, its shape changes from being a prolate to oblate surface. This change increases the corneal and total high-order aberrations, with spherical aberration being the most affected [40-42] and if the lens is decentred, the coma also increases [43]. The increase in high-order aberrations depends on the pupil diameter, as the increase is greater with higher pupils, and the amount of corrected myopia [41]. Goldstone et al. [44] in a retrospective study compared higher-order aberrations for 6-mm pupils induced by orthokeratology with those produced by LASIK in patients with comparable levels of myopia and observed that both treatments increase the higher order aberrations for 6-mm pupils, the spherical aberration being greater in the case of orthokeratology. Gifford et al. and Chen et al., observed that the total spherical aberration with the OK lenses does not change proportionally to the anterior corneal aberration and assumed that there is an ocular adaptation to minimize the increase in spherical aberration, which can be caused by the posterior aspect of the cornea or by the lens as a change in accommodative response $[43,45]$.

The relationship between accommodation and myopia [46, 47] has already been described. Different accommodative demands between the different refractive errors has been shown by McBrien and Millodot [48-50]. The underaccommodation which is still within the bounds of depth of focus is known as accommodative lag. Myopic patients presents larger lag of accommodation compared with emmetropes or hyperopes [51]. According to different studies, an increase of accommodative lag in myopic patients could cause a peripheral hyperopic defocus, and consequently the increase in axial length and the progression of myopia [19, 52-58]. Unfortunately, the results of many studies 
investigating various aspects of the accommodation response in different refraction groups have not provided a unified theory of the relationship between to date about lag accommodation and myopia progression [59-61].

There have been a few studies investigating the changes of accommodative lag in OK contact lenses wearers [62-67], but there has been no consensus about the effect of OK on the accommodative response. Moreover, none of these studies assessed if the accommodative changes are accompanied by internal spherical aberration modifications. The main goal of this study is to evaluate the changes in the accommodative response and internal spherical aberration in myopic children who wear overnight orthokeratology lenses from baseline to three months.

\section{METHODS}

A prospective, randomized and longitudinal study has been performed. Fifty healthy subjects ( 30 female and 20 male) were recruited from the Optometry Clinic of the Faculty of Optics and Optometry (University Complutense of Madrid, Spain). Mean age was $12.00 \pm 2.53$ years (range 8-17 years). Baseline spherical equivalent refractive error was $-2.04 \pm 2.06 \mathrm{D}$. Before beginning the study, the risks and benefits of the treatment were explained, and informed consent was obtained from all subjects (and their parents or guardians). Participants were free to leave the study at any time. The study was conducted in compliance with good clinical practice guidelines [68], institutional review board regulations and the tenets of the Declaration of Helsinki revised in 2013 [69]. Moreover, the study was approved by the Ethics committee of the Hospital Clinico San Carlos (Madrid, Spain).

Inclusion criteria were: myopia in progression during the last year less than or equal to 6.00 dioptres (D), astigmatism less than or equal to $-2,50 \mathrm{D}$ and best spectacle-corrected visual acuity (BSCVA) of 20/25 or better. No previously ortho k lens wearers has been 
included in this study. Exclusion criteria were history of ocular disease and diabetes mellitus. Contact lens wearers were asked to stop wearing their contact lenses one week before the day of examination.

Subjects underwent a previous examination to assess ocular health and to exclude contraindications in the use of orthokeratology contact lenses. All measurements were performed by the same experienced examiner (L.B.). All subjects were fitted with Paragon CRT ${ }^{\mathrm{TM}}$ contact lens (Paragon Vision Sciences, Mesa, AZ) in HDS 100 material (paflufocon $\mathrm{D}, \mathrm{Dk}=100$ barrer) according to manufacturer guidelines. When lenses were prescribed, instructions about the wearing schedule (to wear the lenses at least 6 hours during the night), application, removal, and care system were given to the subjects. Refraction without cycloplegia, high and low uncorrected visual acuity (UCVA) and best corrected visual acuity (BCVA), accommodative lag, horizontal near phoria without correction, corneal topography and corneal and total wavefront aberration were performed. All measurements were performed, at the same time each day for each subject, at baseline (PRE), 1 day (after the first night of lens wear), 1 week, 1 month and 3 months.

\section{Subjective refraction.}

The subjective refraction began with retinoscopy and the results were introduced into a phoropter and a fogging method was used for the subjective refraction. The objective was to find the maximum positive sphere with the BCVA. The astigmatism was adjusted by crossed cylinder technique.

\section{Visual Acuity}

UCVA and BCVA were determined monocularly in photopic luminance conditions (85 cd/m2) using the ETDRS test form Chart Display VX24 (Visionix Ltd., Visionix-Luneau Technologies, Chartres, France) with high contrast (100\%) and low contrast (10\%) letters 
at 4 meters. At baseline and in the follow-up, all subjects underwent monocular testing their best correction and without correction.

\section{Accommodative Lag}

After subjective refractive, Nott's retinoscopy was performed with a metre rule and an ETDRS near chart (Precision Vision, La Salle, Illinois) at $40 \mathrm{~cm}$ positioned in front of the subject. The coefficient of repeatability and mean of difference for Nott's retinoscopy was $\pm 0.66 \mathrm{D}$ and $-0.10 \pm 0.33 \mathrm{D}$, respectively, being the Nott retinoscopy the most repeatable [70-72]. The subject should observe the test binocularly (line 20/40) with under moderate room illumination through the subjective refraction placed in a trial frame. The retinoscopy reflex was observed and in the case of inverse movement being detected, the observer moved closer to the eye until a neutral reflex was found. The result of accommodative response was measured in centimetres and converted to dioptres. The difference in dioptres between the position of the card and the exit pupil of the retinoscope when neutrality is observed was subtracted as $2.5 \mathrm{D}$ accommodative demand. A positive value indicated a lag of accommodation while a negative value indicated a lead of accommodation.

\section{Horizontal near phoria with Alternate Cover Test}

Monocular visual acuity was measured before testing to confirm that the patients had $20 / 32$ or better visual acuity at near. The alternate cover test (ACT) was performed at 40 $\mathrm{cm}$ with the patients wearing their subjective refraction in a trial frame. The examiner instructed the patients to look at a near target with an overall size of approximately 20/40 (Near Chart ETDRS, Good-Lite, Elgin, IL, U.S). First, the examiner determined whether the patient was orthophoric, eso, or exo with the cover paddle; after a prism bar was used to neutralize the movement of the right eye. The prism neutralization endpoint was recorded as the highest prism power that induced no movement before reversal of the 
deviation. Exophoria has been annotated as negative values and esophoria as positive values.

Wavefront aberrometry

To determine the changes in higher order aberration (HOA's), two devices were used: Oculus Pentacam system (Oculus, Wetzlar, Germany) to assess posterior corneal aberration changes and VX110 (Visionix Luneau, France) for anterior corneal and total aberration. The Oculus Pentacam system is a rotating Scheimpflug camera generating during its rotational measuring procedure 3-D images of the anterior segment of the eye. During 2 seconds, the camera rotates $180^{\circ}$ and acquired 25 or 50 images that contain 500 measurement points on the front and back corneal surface to draw a true elevation map. [73-75]The analysis of the anterior eye segment includes a calculation of different types of maps. Parameters mapped with Pentacam included flat keratometry (flat k), steep keratometry (steep k) and back corneal (CB) aberration.

The VX110 is a multi-diagnostic platform that combines Hartmann-Shack based autorefraction and Placido-disk based corneal-topography. The Hartmann-Shack measures 1500 points in $0.2 \mathrm{~s}$ in an area from $2.0 \mathrm{~mm}^{2}$ to $7 \mathrm{~mm}^{2}$. Parameters obtained with VX110 included corneal and total spherical aberration (Z12), corneal and total vertical and horizontal coma (Z7 and Z8) were analysed.

All wavefront data from both devices were reported for a $5.0 \mathrm{~mm}$ pupil diameter measured up to the sixth Zernike order. During the present study spherical aberration (Z12), vertical and horizontal coma (Z7 and Z8) were evaluated and compared for all visits.

\section{Statistical analysis}


Statistical analysis was performed using the SPSS Statistics 23 software (IBM, Chicago, Illinois, USA). For statistical analysis, only one eye of each patient was randomly selected for all variables, except lag of accommodation and horizontal near phoria. Sample size calculations were performed with statistical software Granmo 6.0 (Institut Municipal d'Investigació Mèdica, Barcelona, Spain). The normal distribution of the variables was assessed using the Saphiro-Wilk test. Statistical hypothesis testing was performed to compare the changes of lag of accommodation between before and after orthokeratology contact lens wearing. To analyze the differences between the baseline and the rest of visits, a Student t-test for related samples was used. To evaluate the trend of the different parameters tested during the study, Repeated Measures ANOVA test was performed. Furthermore, the degree of correlation between the different variables between the lag of accommodation at the baseline and the lag of accommodation difference between the baseline and 3-month visits was established with Pearson Correlation test. A statistical significance of $95 \%$ was established $(\mathrm{p}<0.05)$. Results are shown as mean \pm standard deviation.

\section{RESULTS}

Table 1 summarizes the mean values and standard deviation of different variables under study, during the baseline and follow up visits, as refraction, visual acuity, keratometry and near uncorrected phoria. In relation to refraction, the spherical equivalent showed a significant decrease on the first day of OK wearing, compared with the baseline (PRE) (p $<0.05$; student-t test for paired samples). The final spherical equivalent was reached after one week of $\mathrm{OK}$, remaining stable during the rest of the study and being very close to plano. Regarding keratometry readings, both flat and steep radii flattened out during the first week of OK wearing, becoming significant on the first day visit $(\mathrm{p}<0.005$; Student 
t-test for paired samples) and experiencing no changes in the posterior visits. The change in both meridians was around $0.30 \mathrm{~mm}$ of flattening.

The visual acuity was assessed with and without correction and also, in high and low contrast. The BCVA HC remained stable during all visits of the study ( $\mathrm{p}>0.05$; Repeated Measures ANOVA test). However, BCVA LC was worse after the first night of wearing (1.5 lines less), slightly improving in the following visits but maintaining lower visual acuity ( $\mathrm{p}<0.05$; Student t-test for paired samples). Regarding UDVA, both BCVA HC and BCVA LC showed an increase after one day of OK wearing, compared with the baseline ( $\mathrm{p}<0.05$; Student t-test for paired samples). In the case of UDVA, statistically similar values to BCVA were reached before OK wearing during the 3 -month visit $(\mathrm{p}<$ 0.05; Student t-test for paired samples). In contrast, the UDVA LC was lower during the OK wearing compared with BCVA LC before the treatment, being statistically significant ( $p>0.05 ;$ Student t-test for paired samples).

The horizontal near phoria was evaluated before and after 1 and 3 months of OK wearing. There were 25, 24 and 1 subjects who presented orthophoria, exophoria and esophoria, respectively. Analyzing the complete group of subjects, there were statistically significant differences ( $\mathrm{p}<0.05$; student t-test for paired samples) between both follow-up visit and the baseline. However, no changes in horizontal near phoria at 1 and 3-month visits were found in the subject with orthophoria previous to wearing OK lenses. All the subjects continued with orthophoria during OK wearing. Meanwhile, 21 out of 24 subjects with exophoria at the baseline $(6.48 \pm 5.05 \Delta)$ showed a deviation reduction of $3.55 \pm 2.21 \Delta$, finishing with a horizontal near exophoria of $3.39 \pm 4.91 \Delta$ after three months of OK wearing, being statistically significant ( $\mathrm{p}>0.05$; student t-test for paired samples). 
In relation to lag of accommodation, all data have been summarized in Table 2 . There was a lag of accommodation decreasing trend, being statistically significant, from the first day of OK wearing ( $\mathrm{p}<0.05$; student t-test for paired samples), as shown in Fig. 1. Thirtyseven out of fifty subjects (74\%) showed a lag of accommodation decrease, whereas no changes or a slight lag of accommodation increase was found in only 13 out of $50(26 \%)$ at 3 months of $\mathrm{OK}$ wearing. Moreover, a moderate correlation $(0.50>\mathrm{R} 2>0.70)$ between lag of accommodation at the baseline and the lag of accommodation difference between PRE and 3 months visit was found ( $\mathrm{p}<0.05 ; \mathrm{R}=0.748$; Pearson correlation test). It means that subjects with higher lag of accommodation at the baseline will show greater decreasing lag of accommodation during orthokeratology wearing, as shown in Fig. 2.

For better understanding lag of accommodation changes, the total group was divided into two subgroups: lag of accommodation changes group $(n=37)$, being patients who showed less lag of accommodation during orthokeratology lens wearing and, lag of accommodation no changes group $(n=13)$, being patients without changes in the lag of accommodation during orthokeratology lens wearing. Table 2 shows that the lag of accommodation decreasing in lag of accommodation changes group is higher than total group, as mean of $0.55 \mathrm{D}(\mathrm{p}<0.05$; student t-test for paired samples). However, in the lag of accommodation no-changes group the trend was to lag of accommodation increasing, being significant at 1 and 3 months of OK wearing ( $<<0.05$; student t-test for paired samples). Additionally, subjects of the lag of accommodation changes group showed higher lag of accommodation at the baseline visit than subjects of the lag of accommodation no-changes group, being statistically significant $(\mathrm{p}<0.05$; student $\mathrm{t}$-test for paired samples). 
Regarding high order aberrations, there was a significant $4^{\text {th }}$ order spherical aberration increase of anterior corneal and total measurement from the first day of OK wearing, being statistically significant for all visits (Table 3. $\mathrm{p}<0.05$; student $\mathrm{t}$-test for paired samples) (Fig. 3). In contrast, there were no changes for horizontal (Z7) and vertical (Z8) coma neither anterior cornea nor total aberrometry measurement (Table 4. $\mathrm{p}>0.05$; Repeated Measures ANOVA test).

In addition, the internal spherical aberration (total - anterior corneal surface) showed a significant decrease, being $-0.105 \pm 0.006$ ant baseline and $-0.196 \pm 0.203$ at one week of Ok wearing, remaining stable in the following visits (Table 3. $\mathrm{p}<0.05$; student t-test for paired samples) (Fig. 3). To evaluate the source of this change (from posterior cornea or from lens), posterior corneal spherical aberration was measured with Pentacam. There

were no differences between baseline and the follow up visits ( $\mathrm{p}>0.05$; Repeated Measures ANOVA test), suggesting that changes in internal spherical aberration are mainly due to the lens.

\section{DISCUSSION}

The results show a lag of accommodation decrease from the baseline to the one-week visit. A moderate correlation between accommodation lag of accommodation at the baseline and the lag of accommodation difference between PRE and 3 months visit was found. It means that subjects with higher lag of accommodation at the baseline will show greater decrease in accommodative lag of accommodation. A Significant decrease in the internal spherical aberration was found; suggesting that changes in the internal spherical aberration are mainly produced by the lens. 
Refractive correction with OK lenses is achieved by the flattening the central and thinning the mid-peripheral of the corneal epithelium [39, 76, 77]. In addition to the corneal flattening induced by OK lenses wear, the spherical equivalent refraction showed a significant decrease on the first day of use of OK lens, compared to the baseline (PRE) and this change was attributed to the change in corneal power $[78,79]$. The final spherical equivalent refraction in this study was stable and very close to the plano after one week of OK wear, in accordance with other authors $[79,80]$.

The BCVA HC changes were stable during the treatment and at three months reached the same values as before with glasses $[79,81,82]$. However, the BCVA LC did not recover to the pre-treatment levels, getting worse after the first night of use (1.5 lines less). Maldonado Corina et al. [83], evaluated the high and low contrast best-corrected visual acuity from baseline to seven days and no significant differences were found. The difference with this study could be attributed to the design of the OK lens used, as it could affect the overall size of the treatment zone and the low number of patients. It could be hypothesized that this may be one of the causes of the loss of visual quality during OK lenses wearing. Regarding UDVA high and low contrast, the last one showed a significant increase after one night when comparing with baseline [82]

Regarding phoria changes during OK wearing, orthophoric subjects did not show changes, however, 21 of 24 exophoric subjects were less exophoric over the 3-month treatment than at baseline. This finding is in disagreement with Gifford [64] and FelipeMárquez [63], who have described that OK induces a short-term near exophoric trend. The main difference between both studies and the results presented in this study was the age range; this study was performed with children under 17 years old with mild to moderate myopia whilst in the other studies, they were adults. Moreover, the method used 
was different. Measurement accuracy and different dissociation methods may play a crucial role in the comparisons of the different tests for the near-phoria [84]. The importance of these results lies in its potential relationship with myopia development. Children with myopia progression have shown a higher esophoria in close activities, an increase in accommodative lag of accommodation and greater variability in the accommodative response when compared to stable myopes [47, 64]. Therefore, more studies in this area are required.

Studies have concluded that an increase in spherical aberration during orthokeratology treatment may explain the control effect of myopia progression, due to the change in the accommodative system $[76,85]$. On the other hand, different studies have evaluated the changes in the accommodative response after the use of $\mathrm{OK}$ and there was no agreement over the results. A decreasing trend of lag of accommodation has been found in this study from the first day of OK wear, being statistically significant from the first week. These results were in line with those found by Gifford et al [86]., Ren et al. [87] and Han et. [65]. However, Felipe-Márquez et al. [62] did not find changes during the first three months and three years of OK wearing. The results of the current study showed, in $74 \%$ of the subjects, a decrease in the lag of accommodation while Felipe-Marquez et al. did not find changes. A possible reason for these differences could be in the age of the subjects or it could also be due to the methodology differences between the techniques of measuring the lag of accommodation $[21,71]$ or that Felipe-Márquez used two OK lens types.

A moderated and significant correlation was found between lag of accommodation (baseline) and the difference between baseline and three months, in line with Tarrant [88], 
indicating that subjects with higher lag of accommodation at the baseline will show a higher decrease lag of accommodation. To date, the mechanism used for orthokeratology to control the myopia progression has not been demonstrated. Some authors hypothesized about the changes in peripheral refraction $[56,89]$ and others, related the theory of accommodative response as a complementary mechanism to the peripheral refraction. An increase in accommodation could reduce the accommodative lag of accommodation [64, 90]. The evidence of the present results of a lower change in the ocular spherical aberration compared to the corneal aberration and the increases of the accommodative response, support the second hypothesis. However, more studies are needed to demonstrate the potential influence of accommodative response in myopia progression.

Corneal aberrations vary significantly with the use of OK lenses, increasing HOA. This is due to the anterior corneal reshaping and the fact of changing from a prolate to oblate surface [91]. OK has been shown to increase SA in the positive direction which could theoretically infer the reduction of the accommodative response [40, 43].

In the present study, all aberrometric changes in the cornea were obtained on the anterior surface and no significant aberrometric changes were found on the posterior surface during the first three months of OK wear. This shows that the posterior corneal surface seems to be unaffected by the OK lens and that corneal changes occur only on the anterior corneal surface, according to the results obtained by Swarbrick et al $[39,43,92]$ and Tsukiyama et al [93]. However, Owens et al.[94] found a statistically significant flattening after the first week, probably due to a certain amount of corneal oedema. 
However, the current study found that the corneal spherical aberration varied more than the total spherical aberration. As has been shown, there are no aberrometric changes on the posterior corneal surface, indicating that the difference found could be due to a modification of the lens. Some authors have described that changes in internal aberration causes an increase of the accommodative response and therefor a lag of accommodation reduction $[43,95]$. However, in the current study it is not found a strong correlation between the internal aberration and the lag of accommodation. More studies, measuring both parameters with the same device could be needed. Joslin et al [40], found that total SA varied significantly compared with corneal SA after one month of lens use. However, Chen et al. [45] found a significant increase in spherical corneal aberration and a proportional increase in part of the total aberration, which showed a stability of the internal spherical aberration.

The main limitation of this study is the lack of control group. The study design was developed assuming that accommodation does not vary in a control group, fact found in previous studies[22, 63, 64, 66, 96]. It was considered more appropriate to compare the baseline (without orthokeratology lens wearing) with follow up visits (with orthokeratology lens wearing). Other limitations of this study were that the total and corneal aberrations were measured with different instruments, and it would be interesting to confirm these outcomes by measuring both spherical aberration with the same device.

Studies have shown the HOA which had more change with the OK lens was SA (Z12), following vertical and horizontal coma (Z7 y Z8) [40, 43, 97]. Hiraoka et al. had concluded the increase in the coma aberration indicated a decentration of the treatment 
zone [41]. This study found that the vertical and horizontal coma did not change significantly, showing the lens had a proper centration [97].

In summary, three out of four patients presented a decrease in lag of accommodation after the use of OK lenses. In addition, the decrease in the accommodative response was greater in patients with a higher lag of accommodation at the baseline. A decrease in the internal spherical aberration was found, which together with the lag of accommodation change suggests an OK effect on the accommodative response. 


\section{FIGURE LEGENDS}

Fig. 1 Box and whiskers plot about lag of accommodation values at the different visits of the study. ${ }^{*} \mathrm{p}<0.05$; student t-test for paired samples PRE vs. rest of visits; D: Diopters; PRE: baseline; 1D: one day; 1W; one week; 1M: one month; 3M: three months

Fig. 2 Correlation of lag of accommodation pre-treatment and lag of accommodation difference between PRE and 3 months (Pearson correlation; $\mathrm{p}<0.05 ; \mathrm{R}=0.748$ ); $\mathrm{D}$ : Diopters

Fig. 3 Difference of Corneal, internal and total 4th order spherical aberration changes during orthokeratology wearing at different visits. * for corneal aberration; ** for total aberration and $* * *$ for internal aberration: $\mathrm{p}<0.05$; student $\mathrm{t}$-test for paired samples PRE vs. rest of visits; PRE: baseline; 1D: one day; 1W; one week; 1M: one month; 3M: three months 


\section{REFERENCES}

1. Williams KM, Verhoeven VJ, Cumberland P, Bertelsen G, Wolfram C, Buitendijk GH, Hofman A, van Duijn CM, Vingerling JR, Kuijpers RW, Hohn R, Mirshahi A, Khawaja AP, Luben RN, Erke MG, von Hanno T, Mahroo O, Hogg R, Gieger C, Cougnard-Gregoire A, Anastasopoulos E, Bron A, Dartigues JF, Korobelnik JF, Creuzot-Garcher C, Topouzis F, Delcourt C, Rahi J, Meitinger T, Fletcher A, Foster PJ, Pfeiffer N, Klaver CC, Hammond CJ (2015) Prevalence of refractive error in Europe: the European Eye Epidemiology (E(3)) Consortium. European journal of epidemiology 30: 305-315 DOI 10.1007/s10654-015-0010-0

2. Pan CW, Cheng CY, Sabanayagam C, Chew M, Lam J, Ang M, Wong TY (2014) Ethnic variation in central corneal refractive power and steep cornea in Asians. Ophthalmic Epidemiol 21: 99-105 DOI 10.3109/09286586.2014.887735

3. Pan CW, Ramamurthy D, Saw SM (2012) Worldwide prevalence and risk factors for myopia. Ophthalmic \& physiological optics : the journal of the British College of Ophthalmic Opticians (Optometrists) 32: 3-16 DOI 10.1111/j.1475-1313.2011.00884.x

4. Holden BA, Fricke TR, Wilson DA, Jong M, Naidoo KS, Sankaridurg P, Wong TY, Naduvilath TJ, Resnikoff S (2016) Global Prevalence of Myopia and High Myopia and Temporal Trends from 2000 through 2050. Ophthalmology 123: 1036-1042 DOI 10.1016/j.ophtha.2016.01.006

5. Tsai DC, Fang SY, Huang N, Hsu CC, Chen SY, Chiu AW, Liu CJ (2016) Myopia Development Among Young Schoolchildren: The Myopia Investigation Study in Taipei. Investigative ophthalmology \& visual science 57: 6852-6860 DOI 10.1167/iovs.16-20288

6. Saw SM, Gazzard G, Shih-Yen EC, Chua WH (2005) Myopia and associated pathological complications. Ophthalmic \& physiological optics : the journal of the British College of Ophthalmic Opticians (Optometrists) 25: 381-391 DOI 10.1111/j.1475-1313.2005.00298.x

7. Flitcroft DI (2012) The complex interactions of retinal, optical and environmental factors in myopia aetiology. Progress in Retinal and Eye Research 31: 622-660 DOI http://dx.doi.org/10.1016/j.preteyeres.2012.06.004

8. Chen CY, Scurrah KJ, Stankovich J, Garoufalis P, Dirani M, Pertile KK, Richardson AJ, Mitchell P, Baird PN (2007) Heritability and shared environment estimates for myopia and associated ocular biometric traits: the Genes in Myopia (GEM) family study. Human genetics 121: 511-520 DOI 10.1007/s00439-006-0312-0

9. Cooper J, Tkatchenko AV (2018) A Review of Current Concepts of the Etiology and Treatment of Myopia. Eye \& contact lens 44: 231-247 DOI 10.1097/icl.0000000000000499

10. Tedja MS, Haarman AEG, Meester-Smoor MA, Kaprio J, Mackey DA, Guggenheim JA, Hammond CJ, Verhoeven VJM, Klaver CCW (2019) IMI Myopia Genetics Report. Investigative ophthalmology \& visual science 60: M89-m105 DOI 10.1167/iovs.18-25965

11. Cheng CY, Schache M, Ikram MK, Young TL, Guggenheim JA, Vitart V, MacGregor S, Verhoeven VJ, Barathi VA, Liao J, Hysi PG, Bailey-Wilson JE, St Pourcain B, Kemp JP, McMahon G, Timpson NJ, Evans DM, Montgomery 
GW, Mishra A, Wang YX, Wang JJ, Rochtchina E, Polasek O, Wright AF, Amin N, van Leeuwen EM, Wilson JF, Pennell CE, van Duijn CM, de Jong PT, Vingerling JR, Zhou X, Chen P, Li R, Tay WT, Zheng Y, Chew M, Burdon KP, Craig JE, Iyengar SK, Igo RP, Jr., Lass JH, Jr., Chew EY, Haller T, Mihailov E, Metspalu A, Wedenoja J, Simpson CL, Wojciechowski R, Hohn R, Mirshahi A, Zeller T, Pfeiffer N, Lackner KJ, Bettecken T, Meitinger T, Oexle K, Pirastu M, Portas L, Nag A, Williams KM, Yonova-Doing E, Klein R, Klein BE, Hosseini SM, Paterson AD, Makela KM, Lehtimaki T, Kahonen M, Raitakari O, Yoshimura N, Matsuda F, Chen LJ, Pang CP, Yip SP, Yap MK, Meguro A, Mizuki N, Inoko H, Foster PJ, Zhao JH, Vithana E, Tai ES, Fan Q, Xu L, Campbell H, Fleck B, Rudan I, Aung T, Hofman A, Uitterlinden AG, Bencic G, Khor CC, Forward H, Parssinen O, Mitchell P, Rivadeneira F, Hewitt AW, Williams C, Oostra BA, Teo YY, Hammond CJ, Stambolian D, Mackey DA, Klaver CC, Wong TY, Saw SM, Baird PN (2013) Nine loci for ocular axial length identified through genome-wide association studies, including shared loci with refractive error. American journal of human genetics 93: 264-277 DOI 10.1016/j.ajhg.2013.06.016

12. Lyhne N, Sjolie AK, Kyvik KO, Green A (2001) The importance of genes and environment for ocular refraction and its determiners: a population based study among 20-45 year old twins. The British journal of ophthalmology 85: 14701476

13. Pacella R, McLellan J, Grice K, Del Bono EA, Wiggs JL, Gwiazda JE (1999) Role of genetic factors in the etiology of juvenile-onset myopia based on a longitudinal study of refractive error. Optometry and vision science : official publication of the American Academy of Optometry 76: 381-386

14. Ip JM, Saw SM, Rose KA, Morgan IG, Kifley A, Wang JJ, Mitchell P (2008) Role of near work in myopia: findings in a sample of Australian school children. Investigative ophthalmology \& visual science 49: 2903-2910 DOI 10.1167/iovs.07-0804

15. Xiong S, Sankaridurg P, Naduvilath T, Zang J, Zou H, Zhu J, Lv M, He X, Xu X (2017) Time spent in outdoor activities in relation to myopia prevention and control: a meta-analysis and systematic review. Acta ophthalmologica 95: 551566 DOI 10.1111/aos.13403

16. Wildsoet CF, Chia A, Cho P, Guggenheim JA, Polling JR, Read S, Sankaridurg P, Saw SM, Trier K, Walline JJ, Wu PC, Wolffsohn JS (2019) IMI Interventions Myopia Institute: Interventions for Controlling Myopia Onset and Progression Report. Investigative ophthalmology \& visual science 60: M106m131 DOI 10.1167/iovs.18-25958

17. Berntsen DA, Mutti DO, Zadnik K (2010) Study of theories about myopia progression (STAMP) design and baseline data. Optometry and Vision Science 87: 823-832 DOI 10.1097/OPX.0b013e3181f6f776

18. Gwiazda J, Biiuer J, Grice K, Thorn F (1997) Precursors of myopia in children. Investigative Ophthalmology and Visual Science 38

19. Gwiazda J, Thorn F, Bauer J, Held R (1993) Myopic children show insufficient accommodative response to blur. Investigative ophthalmology \& visual science 34: 690-694

20. Gwiazda JE, Hyman L, Norton TT, Hussein MEM, Marsh-Tootle W, Manny R, Wang Y, Everett D (2004) Accommodation and related risk factors associated with myopia progression and their interaction with treatment in COMET 
children. Investigative Ophthalmology and Visual Science 45: 2143-2151 DOI 10.1167/iovs.03-1306

21. Manny RE, Chandler DL, Scheiman MM, Gwiazda JE, Cotter SA, Everett DF, Holmes JM, Hyman LG, Kulp MT, Lyon DW, Marsh-Tootle W, Matta N, Melia BM, Norton TT, Repka MX, Silbert DI, Weissberg EM, Gwiazda J, Chandler D, Cotter S, Hyman L, Kulp M, Melia M, Norton T, Scheiman M, Silbert D, Weissberg E (2009) Accommodative lag by autorefraction and two dynamic retinoscopy methods. Optometry and Vision Science 86: 233-243 DOI 10.1097/OPX.0b013e318197180c

22. Mutti DO, Mitchell GL, Hayes JR, Jones LA, Moeschberger ML, Cotter SA, Kleinstein RN, Manny RE, Twelker JD, Zadnik K, Hullett S, Sims J, Weeks R, Williams S, Calvin L, Shipp MD, Friedman NE, Qualley P, Wickum SM, Kim A, Mathis B, Batres M, Henry S, Wensveen JM, Crossnoe CJ, Tom SL, McLeod JA, Quiralte JC, Yu JA, Chu RJ, Barnhardt CN, Chang J, Huang K, Bridgeford R, Chu C, Kwon S, Lee G, Lee J, Lee R, Maeda R, Emerson R, Leonhardt T, Messer D, Flores D, Bhakta R, Malone JM, Sheng H, Omlor H, Rahmani M, Brickman J, Wang A, Arner P, Taylor S, Nguyen MT, Walker TW, Barrett L, Sinnott L, Wessel P, Swartzendruber JN, Everett DF (2006) Accommodative lag before and after the onset of myopia. Investigative Ophthalmology and Visual Science 47: 837-846 DOI 10.1167/iovs.05-0888

23. Gwiazda J, Grice K, Thorn F (1999) Response AC/A ratios are elevated in myopic children. Ophthalmic \& physiological optics : the journal of the British College of Ophthalmic Opticians (Optometrists) 19: 173-179

24. Mutti DO, Mitchell GL, Jones-Jordan LA, Cotter SA, Kleinstein RN, Manny RE, Twelker JD, Zadnik K (2017) The response AC/A ratio before and after the onset of myopia. Investigative Ophthalmology and Visual Science 58: 15941602 DOI 10.1167/iovs.16-19093

25. Wu PC, Chuang MN, Choi J, Chen H, Wu G, Ohno-Matsui K, Jonas JB, Cheung CMG (2018) Update in myopia and treatment strategy of atropine use in myopia control. Eye (London, England) DOI 10.1038/s41433-018-0139-7

26. Tarutta EP, Iomdina EN, Kvaratskheliya NG, Milash SV, Kruzhkova GV (2017) [Peripheral refraction: cause or effect of refraction development?]. Vestn Oftalmol 133: 70-74 DOI 10.17116/oftalma2017133170-74

27. Yang X, Li Z, Zeng J (2016) A Review of the Potential Factors Influencing Myopia Progression in Children Using Orthokeratology. Asia-Pacific journal of ophthalmology (Philadelphia, Pa) 5: 429-433 DOI 10.1097/apo.0000000000000242

28. Paune J, Thivent S, Armengol J, Quevedo L, Faria-Ribeiro M, GonzalezMeijome JM (2016) Changes in Peripheral Refraction, Higher-Order Aberrations, and Accommodative Lag With a Radial Refractive Gradient Contact Lens in Young Myopes. Eye \& contact lens 42: 380-387 DOI 10.1097/icl.0000000000000222

29. Huang J, Wen D, Wang Q, McAlinden C, Flitcroft I, Chen H, Saw SM, Chen H, Bao F, Zhao Y, Hu L, Li X, Gao R, Lu W, Du Y, Jinag Z, Yu A, Lian H, Jiang Q, Yu Y, Qu J (2016) Efficacy Comparison of 16 Interventions for Myopia Control in Children: A Network Meta-analysis. Ophthalmology 123: 697-708 DOI 10.1016/j.ophtha.2015.11.010

30. Wolffsohn JS, Calossi A, Cho P, Gifford K, Jones L, Li M, Lipener C, Logan NS, Malet F, Matos S, Meijome JM, Nichols JJ, Orr JB, Santodomingo-Rubido J, Schaefer T, Thite N, van der Worp E, Zvirgzdina M (2016) Global trends in 
myopia management attitudes and strategies in clinical practice. Contact lens \& anterior eye : the journal of the British Contact Lens Association 39: 106-116 DOI 10.1016/j.clae.2016.02.005

31. Kang P (2018) Optical and pharmacological strategies of myopia control. Clinical \& experimental optometry 101: 321-332 DOI 10.1111/cxo.12666

32. Lipson MJ, Brooks MM, Koffler BH (2018) The Role of Orthokeratology in Myopia Control: A Review. Eye \& contact lens 44: 224-230 DOI 10.1097/icl.0000000000000520

33. Lee YC, Wang JH, Chiu CJ (2017) Effect of Orthokeratology on myopia progression: twelve-year results of a retrospective cohort study. BMC ophthalmology 17: 243 DOI 10.1186/s12886-017-0639-4

34. Hiraoka T, Sekine Y, Okamoto F, Mihashi T, Oshika T (2018) Safety and efficacy following 10-years of overnight orthokeratology for myopia control. Ophthalmic \& physiological optics : the journal of the British College of Ophthalmic Opticians (Optometrists) 38: 281-289 DOI 10.1111/opo.12460

35. Li SM, Kang MT, Wu SS, Liu LR, Li H, Chen Z, Wang N (2016) Efficacy, Safety and Acceptability of Orthokeratology on Slowing Axial Elongation in Myopic Children by Meta-Analysis. Current eye research 41: 600-608 DOI 10.3109/02713683.2015.1050743

36. Anstice NS, Phillips JR (2011) Effect of dual-focus soft contact lens wear on axial myopia progression in children. Ophthalmology 118: 1152-1161 DOI 10.1016/j.ophtha.2010.10.035

37. Ji Q, Yoo YS, Alam H, Yoon G (2018) Through-focus optical characteristics of monofocal and bifocal soft contact lenses across the peripheral visual field. Ophthalmic \& physiological optics : the journal of the British College of Ophthalmic Opticians (Optometrists) 38: 326-336 DOI 10.1111/opo.12452

38. Liu YM, Xie P (2016) The Safety of Orthokeratology--A Systematic Review. Eye \& contact lens 42: 35-42 DOI 10.1097/icl.0000000000000219

39. Swarbrick HA, Wong G, O'Leary DJ (1998) Corneal response to orthokeratology. Optometry and vision science : official publication of the American Academy of Optometry 75: 791-799

40. Joslin CE, Wu SM, McMahon TT, Shahidi M (2003) Higher-order wavefront aberrations in corneal refractive therapy. Optometry and vision science : official publication of the American Academy of Optometry 80: 805-811

41. Hiraoka T, Matsumoto Y, Okamoto F, Yamaguchi T, Hirohara Y, Mihashi T, Oshika T (2005) Corneal higher-order aberrations induced by overnight orthokeratology. Am J Ophthalmol 139: 429-436 DOI 10.1016/j.ajo.2004.10.006

42. Faria-Ribeiro M, Belsue RN, López-Gil N, González-Meíjome JM (2016) Morphology, topography, and optics of the orthokeratology cornea. Journal of biomedical optics 21 DOI 10.1117/1.JBO.21.7.075011

43. Gifford P, Li M, Lu H, Miu J, Panjaya M, Swarbrick HA (2013) Corneal versus ocular aberrations after overnight orthokeratology. Optometry and Vision Science 90: 439-447 DOI 10.1097/OPX.0b013e31828ec594

44. Goldstone RN, Yildiz EH, Fan VC, Asbell PA (2010) Changes in higher order wavefront aberrations after contact lens corneal refractive therapy and LASIK surgery. Journal of refractive surgery (Thorofare, NJ : 1995) 26: 348-355 DOI $10.3928 / 1081597 x-20100218-03$ 
45. Chen Q, Li M, Yuan Y, Me R, Yu Y, Shi G, Ke B (2017) Interaction between Corneal and Internal Ocular Aberrations Induced by Orthokeratology and Its Influential Factors. Biomed Res Int 2017: 3703854 DOI 10.1155/2017/3703854

46. de Jong P (2018) Myopia: its historical contexts. The British journal of ophthalmology 102: 1021-1027 DOI 10.1136/bjophthalmol-2017-311625

47. Harb E, Thorn F, Troilo D (2006) Characteristics of accommodative behavior during sustained reading in emmetropes and myopes. Vision research 46: 25812592 DOI 10.1016/j.visres.2006.02.006

48. McBrien NA, Millodot M (1987) The relationship between tonic accommodation and refractive error. Investigative ophthalmology \& visual science 28: 997-1004

49. McBrien NA, Millodot M (1986) The effect of refractive error on the accommodative response gradient. Ophthalmic \& physiological optics : the journal of the British College of Ophthalmic Opticians (Optometrists) 6: 145149

50. Millodot M (2015) The effect of refractive error on the accommodative response gradient: A summary and update. Ophthalmic and Physiological Optics 35: 607612 DOI 10.1111/opo.12241

51. Allen PM, O'Leary DJ (2006) Accommodation functions: Co-dependency and relationship to refractive error. Vision research 46: 491-505 DOI 10.1016/j.visres.2005.05.007

52. Winawer J, Zhu X, Choi J, Wallman J (2005) Ocular compensation for alternating myopic and hyperopic defocus. Vision research 45: 1667-1677 DOI 10.1016/j.visres.2004.12.013

53. Seidemann A, Schaeffel F, Guirao A, Lopez-Gil N, Artal P (2002) Peripheral refractive errors in myopic, emmetropic, and hyperopic young subjects. Journal of the Optical Society of America A, Optics, image science, and vision 19: 2363-2373

54. Schaeffel F, Glasser A, Howland HC (1988) Accommodation, refractive error and eye growth in chickens. Vision research 28: 639-657

55. Hung LF, Crawford ML, Smith EL (1995) Spectacle lenses alter eye growth and the refractive status of young monkeys. Nature medicine 1:761-765

56. Smith EL, 3rd, Ramamirtham R, Qiao-Grider Y, Hung LF, Huang J, Kee CS, Coats D, Paysse E (2007) Effects of foveal ablation on emmetropization and form-deprivation myopia. Investigative ophthalmology \& visual science 48: 3914-3922 DOI 10.1167/iovs.06-1264

57. Smith EL, 3rd, Kee CS, Ramamirtham R, Qiao-Grider Y, Hung LF (2005) Peripheral vision can influence eye growth and refractive development in infant monkeys. Investigative ophthalmology \& visual science 46: 3965-3972 DOI 10.1167/iovs.05-0445

58. Hiraoka T, Kakita T, Okamoto F, Oshika T (2015) Influence of ocular wavefront aberrations on axial length elongation in myopic children treated with overnight orthokeratology. Ophthalmology 122: 93-100 DOI 10.1016/j.ophtha.2014.07.042

59. Mutti DO, Sinnott LT, Mitchell GL, Jones-Jordan LA, Moeschberger ML, Cotter SA, Kleinstein RN, Manny RE, Twelker JD, Zadnik K (2011) Relative peripheral refractive error and the risk of onset and progression of myopia in children. Investigative ophthalmology \& visual science 52: 199-205 DOI 10.1167/iovs.09-4826 
60. Atchison DA, Li SM, Li H, Li SY, Liu LR, Kang MT, Meng B, Sun YY, Zhan SY, Mitchell P, Wang N (2015) Relative Peripheral Hyperopia Does Not Predict Development and Progression of Myopia in Children. Investigative ophthalmology \& visual science 56: 6162-6170 DOI 10.1167/iovs.15-17200

61. Wolffsohn JS, Kollbaum PS, Berntsen DA, Atchison DA, Benavente A, Bradley A, Buckhurst H, Collins M, Fujikado T, Hiraoka T, Hirota M, Jones D, Logan NS, Lundström L, Torii H, Read SA, Naidoo K (2019) IMI - Clinical Myopia Control Trials and Instrumentation ReportIMI - Clinical Myopia Control Trials and Instrumentation. Investigative ophthalmology \& visual science 60: M132M160 DOI 10.1167/iovs.18-25955

62. Felipe-Marquez G, Nombela-Palomo M, Cacho I, Nieto-Bona A (2015) Accommodative changes produced in response to overnight orthokeratology. Graefe's Archive for Clinical and Experimental Ophthalmology 253: 619-626 DOI 10.1007/s00417-014-2865-2

63. Felipe-Marquez G, Nombela-Palomo M, Palomo-Alvarez C, Cacho I, NietoBona A (2017) Binocular function changes produced in response to overnight orthokeratology. Graefe's archive for clinical and experimental ophthalmology = Albrecht von Graefes Archiv fur klinische und experimentelle Ophthalmologie 255: 179-188 DOI 10.1007/s00417-016-3554-0

64. Gifford K, Gifford P, Hendicott PL, Schmid KL (2017) Near binocular visual function in young adult orthokeratology versus soft contact lens wearers. Contact lens \& anterior eye : the journal of the British Contact Lens Association 40: 184-189 DOI 10.1016/j.clae.2017.01.003

65. Han X, Xu D, Ge W, Wang Z, Li X, Liu W (2017) A Comparison of the Effects of Orthokeratology Lens, Medcall Lens, and Ordinary Frame Glasses on the Accommodative Response in Myopic Children. Eye \& contact lens DOI 10.1097/icl.0000000000000390

66. Yang Y, Wang L, Li P, Li J (2018) Accommodation function comparison following use of contact lens for orthokeratology and spectacle use in myopic children: a prospective controlled trial. Int J Ophthalmol 11: 1234-1238 DOI 10.18240/ijo.2018.07.26

67. Kang P, Watt K, Chau T, Zhu J, Evans BJW, Swarbrick H (2018) The impact of orthokeratology lens wear on binocular vision and accommodation: A short-term prospective study. Contact lens \& anterior eye : the journal of the British Contact Lens Association 41: 501-506 DOI 10.1016/j.clae.2018.08.002

68. Cho P, Cheung SW, Mountford J, White P (2008) Good clinical practice in orthokeratology. Cont Lens Anterior Eye 31: 17-28 DOI

10.1016/j.clae.2007.07.003

69. World Medical A (2013) World Medical Association Declaration of Helsinki: ethical principles for medical research involving human subjects. JAMA 310: 2191-2194 DOI 10.1001/jama.2013.281053

70. Antona B, Sanchez I, Barrio A, Barra F, Gonzalez E (2009) Intra-examiner repeatability and agreement in accommodative response measurements. Ophthalmic \& physiological optics : the journal of the British College of Ophthalmic Opticians (Optometrists) 29: 606-614 DOI 10.1111/j.14751313.2009.00679.x

71. del Pilar Cacho M, Garcia-Munoz A, Garcia-Bernabeu JR, Lopez A (1999) Comparison between MEM and Nott dynamic retinoscopy. Optometry and vision science : official publication of the American Academy of Optometry 76: 650-655 
72. Nguyen AT, Wayne JL, Ravikumar A, Manny RE, Anderson HA (2018) Accommodative accuracy by retinoscopy versus autorefraction spherical equivalent or horizontal meridian power. Clinical \& experimental optometry 101: 778-785 DOI 10.1111/cxo.12678

73. Lackner B, Schmidinger G, Skorpik C (2005) Validity and repeatability of anterior chamber depth measurements with Pentacam and Orbscan. Optometry and vision science : official publication of the American Academy of Optometry 82: $858-861$

74. Jonuscheit S (2014) Data extraction and reporting strategies of studies assessing non-central corneal thickness by Pentacam: a review. Contact lens \& anterior eye : the journal of the British Contact Lens Association 37: 323-330 DOI 10.1016/j.clae.2014.06.004

75. Crawford AZ, Patel DV, McGhee CN (2013) Comparison and repeatability of keratometric and corneal power measurements obtained by Orbscan II, Pentacam, and Galilei corneal tomography systems. Am J Ophthalmol 156: 5360 DOI 10.1016/j.ajo.2013.01.029

76. Faria-Ribeiro M, Belsue RN, Lopez-Gil N, Gonzalez-Meijome JM (2016) Morphology, topography, and optics of the orthokeratology cornea. Journal of biomedical optics 21: 75011 DOI 10.1117/1.JBO.21.7.075011

77. Nieto-Bona A, Gonzalez-Mesa A, Nieto-Bona MP, Villa-Collar C, LorenteVelazquez A (2011) Short-term effects of overnight orthokeratology on corneal cell morphology and corneal thickness. Cornea 30: 646-654 DOI 10.1097/ICO.0b013e31820009bc

78. Marcotte-Collard R, Simard P, Michaud L (2018) Analysis of Two Orthokeratology Lens Designs and Comparison of Their Optical Effects on the Cornea. Eye \& contact lens DOI 10.1097/icl.0000000000000495

79. Swarbrick HA (2006) Orthokeratology review and update. Clinical \& experimental optometry 89: 124-143 DOI 10.1111/j.1444-0938.2006.00044.x

80. Lu D, Gu T, Lin W, Li N, Gong B, Wei R (2018) Efficacy of Trial Fitting and Software Fitting for Orthokeratology Lens: One-Year Follow-Up Study. Eye Contact Lens 44: 339-343 DOI 10.1097/ICL.0000000000000539

81. Sorbara L, Fonn D, Simpson T, Lu F, Kort R (2005) Reduction of myopia from corneal refractive therapy. Optometry and vision science : official publication of the American Academy of Optometry 82: 512-518

82. Nichols JJ, Marsich MM, Nguyen M, Barr JT, Bullimore MA (2000) Overnight orthokeratology. Optometry and vision science : official publication of the American Academy of Optometry 77: 252-259

83. Maldonado-Codina C, Efron S, Morgan P, Hough T, Efron N (2005) Empirical versus trial set fitting systems for accelerated orthokeratology. Eye \& contact lens 31: 137-147

84. Sanker N, Prabhu A, Ray A (2012) A comparison of near-dissociated heterophoria tests in free space. Clinical \& experimental optometry 95: 638-642 DOI 10.1111/j.1444-0938.2012.00785.x

85. Philip K, Sankaridurg P, Holden B, Ho A, Mitchell P (2014) Influence of higher order aberrations and retinal image quality in myopisation of emmetropic eyes. Vision research 105: 233-243 DOI 10.1016/j.visres.2014.10.003

86. Gifford K, Gifford P, Hendicott PL, Schmid KL (2017) Near binocular visual function in young adult orthokeratology versus soft contact lens wearers. Contact Lens and Anterior Eye 40: 184-189 DOI 10.1016/j.clae.2017.01.003 
87. Ren Q, Yue H, Zhou Q (2016) Effects of orthokeratology lenses on the magnitude of accommodative lag and accommodative convergence/accommodation. Journal of Central South University (Medical Sciences) 41: 169-173 DOI 10.11817/j.issn.1672-7347.2016.02.009

88. Tarrant J, Liu Y, Wildsoet CF (2009) Orthokeratology Can Decrease the Accommodative Lag in Myopes. Investigative ophthalmology \& visual science 50: 4294-4294

89. Charman WN, Mountford J, Atchison DA, Markwell EL (2006) Peripheral refraction in orthokeratology patients. Optometry and vision science : official publication of the American Academy of Optometry 83: 641-648 DOI 10.1097/01.opx.0000232840.66716.af

90. Ren Q, Yue H, Zhou Q (2016) [Effects of orthokeratology lenses on the magnitude of accommodative lag and accommodativeconvergence/accommodation]. Zhong nan da xue xue bao Yi xue ban = Journal of Central South University Medical sciences 41: 169-173 DOI 10.11817/j.issn.1672-7347.2016.02.009

91. Lian Y, Shen M, Huang S, Yuan Y, Wang Y, Zhu D, Jiang J, Mao X, Wang J, Lu F (2014) Corneal reshaping and wavefront aberrations during overnight orthokeratology. Eye \& contact lens 40: 161-168 DOI 10.1097/icl.0000000000000031

92. Yoon JH, Swarbrick HA (2013) Posterior corneal shape changes in myopic overnight orthokeratology. Optometry and vision science : official publication of the American Academy of Optometry 90: 196-204 DOI 10.1097/OPX.0b013e31828121eb

93. Tsukiyama J, Miyamoto Y, Higaki S, Fukuda M, Shimomura Y (2008) Changes in the anterior and posterior radii of the corneal curvature and anterior chamber depth by orthokeratology. Eye \& contact lens 34: 17-20 DOI 10.1097/ICL.0b013e3180515299

94. Owens H, Garner LF, Craig JP, Gamble G (2004) Posterior corneal changes with orthokeratology. Optometry and vision science : official publication of the American Academy of Optometry 81: 421-426

95. Lopez-Gil N, Fernandez-Sanchez V (2010) The change of spherical aberration during accommodation and its effect on the accommodation response. Journal of vision 10: 12 DOI 10.1167/10.13.12

96. Felipe-Marquez G, Nombela-Palomo M, Cacho I, Nieto-Bona A (2015) Accommodative changes produced in response to overnight orthokeratology. Graefes Arch Clin Exp Ophthalmol 253: 619-626 DOI 10.1007/s00417-0142865-2

97. Berntsen DA, Barr JT, Mitchell GL (2005) The effect of overnight contact lens corneal reshaping on higher-order aberrations and best-corrected visual acuity. Optometry and vision science : official publication of the American Academy of Optometry 82: 490-497 


\section{COMPLIANCE WITH ETHICAL STANDARDS}

\section{* Disclosure of potential conflicts of interest}

Laura Batres declares that he/she has no conflict of interest. Sara Peruzzo declares that he/she has no conflict of interest. Maria Serramito declares that he/she has no conflict of interest. Gonzalo Carracedo declares that he/she has no conflict of interest.

\section{* Research involving human participants and/or animals}

All procedures performed in studies involving human participants were in accordance with the ethical standards of the institutional and/or national research committee and with the 1964 Helsinki declaration and its later amendments or comparable ethical standards. The study was approved by the ethical committee of Hospital Clinico San Carlos, being the approval document number: $16 / 371-\mathrm{E}$

\section{* Informed consent}


Informed consent was obtained from all individual participants included in the study.

\section{* Funding}

No funding was received for this research. 